\title{
Durability testing of photoelectrochemical hydrogen production under day/night light cycled conditions
}

Bae, Dowon; Seger, Brian; Vesborg, Peter Christian Kjærgaard; Hansen, Ole; Chorkendorff, Ib

Published in:

ChemElectroChem

Link to article, DOI:

$10.1002 /$ celc. 201800918

Publication date:

2019

Document Version

Peer reviewed version

Link back to DTU Orbit

Citation (APA):

Bae, D., Seger, B., Vesborg, P. C. K., Hansen, O., \& Chorkendorff, I. (2019). Durability testing of photoelectrochemical hydrogen production under day/night light cycled conditions. ChemElectroChem, 6(1), 106-109. https://doi.org/10.1002/celc.201800918

\section{General rights}

Copyright and moral rights for the publications made accessible in the public portal are retained by the authors and/or other copyright owners and it is a condition of accessing publications that users recognise and abide by the legal requirements associated with these rights.

- Users may download and print one copy of any publication from the public portal for the purpose of private study or research.

- You may not further distribute the material or use it for any profit-making activity or commercial gain

- You may freely distribute the URL identifying the publication in the public portal 


\section{FUNDAMENTALS \& APPLICATIONS \\ CHEMELECTROCHEM}

ANALYSIS \& CATALYSIS, BIO \& NANO, ENERGY \& MORE

\section{Accepted Article}

Title: Durability testing of photoelectrochemical hydrogen production under day/night light cycled conditions

Authors: Dowon Bae, Brian Seger, Peter C.K. Vesborg, Ole Hansen, and Ib Chorkendorff

This manuscript has been accepted after peer review and appears as an Accepted Article online prior to editing, proofing, and formal publication of the final Version of Record (VoR). This work is currently citable by using the Digital Object Identifier (DOI) given below. The VoR will be published online in Early View as soon as possible and may be different to this Accepted Article as a result of editing. Readers should obtain the VoR from the journal website shown below when it is published to ensure accuracy of information. The authors are responsible for the content of this Accepted Article.

To be cited as: ChemElectroChem 10.1002/celc.201800918

Link to VoR: http://dx.doi.org/10.1002/celc.201800918 


\title{
Durability testing of photoelectrochemical hydrogen production under day/night light cycled conditions
}

\author{
Dowon Bae, ${ }^{[a] \dagger}$ Brian Seger, ${ }^{[a]}$ Ole Hansen, ${ }^{[a, b]}$ Peter C.K. Vesborg,,${ }^{[a]}$ and Ib Chorkendorff ${ }^{[a] *}$
}

\begin{abstract}
This work investigates long-term photoelectrochemical hydrogen evolution (82 days) in $1 \mathrm{M} \mathrm{HClO}_{4}$ using a $\mathrm{TiO}_{2}: \mathrm{H}$ protected crystalline Si-based photocathode with metal-oxide-semiconductor (MOS) junctions. It is shown that day/night cycling leads to relatively rapid performance degradation while photocurrent under the continuous light condition is relatively stable. We observed that the performance loss is mainly due to contamination of catalytic surface with carbonaceous material. By ultraviolet (UV) light exposure, we also observed that the activity can be restored likely owing to the photocatalytic degradation of organics on the $\mathrm{TiO}_{2}$ protection layer.
\end{abstract}

A photoelectrochemical (PEC) approach to convert solar energy to useful fuels or chemicals is highly appealing due to the fact that two processes can be integrated into a single device, thus potentially lowering capital costs. ${ }^{[1]}$ While a wide variety of PEC reactions have recently seen great interest, direct water splitting into $\mathrm{H}_{2}$ and $\mathrm{O}_{2}$ remains a good benchmarking reaction because of the facile $\mathrm{H}_{2}$ catalysis and the lack of any issues related to product selectivity. A dual absorber (tandem) approach, which uses a high band gap and low band gap photoelectrode in series, has been widely accepted to give the optimum efficiency in AM1.5 sunlight as previous modelling has shown. ${ }^{[2,3]}$

This field has primarily focused on optimizing the photovoltage and current needed to split water efficiently, and these efforts have borne fruit with multiple works showing greater than $10 \%$ efficient devices. ${ }^{[4,5]}$ Recently, attention has turned towards stability with most publications about devices having stabilities for at least 24 hours. ${ }^{[6,7]}$ On the other hand, long-term durability tests (> 1 month) have been much more limited. Maier et al. demonstrated relatively low, but stable photocurrent under the HER conditions for 60 days in $1 \mathrm{M} \mathrm{HCl}$ using a Pt-coated crystalline silicon (c-Si), ${ }^{[8]}$ while a recent study by the Jaramillo group used a thin $\mathrm{MoS}_{2}$ protected c-Si to show durability for up to 62 days. ${ }^{[9]}$ While these long-term tests demonstrate steady state operational stability of these devices, practical devices will be subjected to daily day/night cycling, which will vary the potential at the semiconductor/protection layer/catalyst-electrolyte

[a] Dr. D. Bae, Prof. B. Seger, Prof. O. Hansen, Prof. P.C.K. Vesborg, Prof. I. Chorkendorff*

Surface Physics \& Catalysis (SurfCat)

Department of Physics

Technical University of Denmark

Fysikvej B311, 2800 Kongens Lyngby (Denmark)

E-mail: ibchork@fysik.dtu.dk

[b] Prof. O. Hansen

Department of Micro- and Nanotechnology

Technical University of Denmark

Ørsteds Plads B344, 2800 Kongens Lyngby (Denmark)

$\dagger \quad$ Current address: Materials for Energy Conversion and Storage (MECS), Department of Chemical Engineering, Delft University of Technology

Corresponding author

Supporting information for this article is given via a link at the end of the document.((Please delete this text if not appropriate)) interface. Thus there is a need to understand how this cycling will affect stability.

When an electrode is continually photoirradiated the interface between the photocathode and the electrolyte is held at a constant potential, thus stability is only measured at that potential. However, when the cell is in the dark the interface potential switches to that of the liquid. If the surface potential reaches sufficiently anodic conditions in the dark, it could potentially oxidize the semiconductor or catalyst. If this oxidized state is water soluble, this will lead to corrosion. ${ }^{[6,10]}$ Pourbaix diagram analysis can give an indication of where corrosion would be expected, but Pourbaix diagrams are based on thermodynamics and do not consider kinetic effects. ${ }^{[11]} \mathrm{Viz}$. a real system could be kinetically stable even if thermodynamics indicate instability. Thus experimental work is needed to accurately determine corrosion rates. ${ }^{[6,12,13]}$ Works by Young ${ }^{[12]}$ and Bae et al., ${ }^{[14]}$ have shown that $\mathrm{GaAs}$ and $\mathrm{Si}$, respectively, can be effectively protected at open circuit potential in the dark. However, cycling between two potentials can sometimes cause serious corrosion as exemplified by catalyst corrosion in the PEM fuel cells. ${ }^{[15]}$

In a previous study, ${ }^{[16]}$ we presented a long-term photocathodic $\mathrm{H}_{2}$ evolution experiment in $1 \mathrm{M} \mathrm{HClO}_{4}$ under continuous light at a fixed potential (Fig. 1a) for 41 days using a $\mathrm{TiO}_{2}$ protected MOSbased Si photocathode with $\mathrm{Pt}$ nanoparticles (Fig. 1b, more details are shown in the ESIT). This study is a continuation of that previous study where we continue to analyse the same electrode by starting to cycle the electrode between light and dark conditions (with frequency of 12 hours light on/off, see Fig. 1a). The advantage of using this approach is that the steady-state stability of the device under continuous light is well characterized, thus allowing us to accurately isolate the effects due purely to cycling. In other words, we have taken the electrode from ref [15] that has already operated for 41 days, and then start to cycle it between illuminated and dark conditions.

The results of this experiment are shown in Fig. 2a. It shows the long-term stability (AM 1.5G with 635 nm long-pass filter, see Fig. S1) of the $\mathrm{TiO}_{2}$ protected photocathode sample measured at a

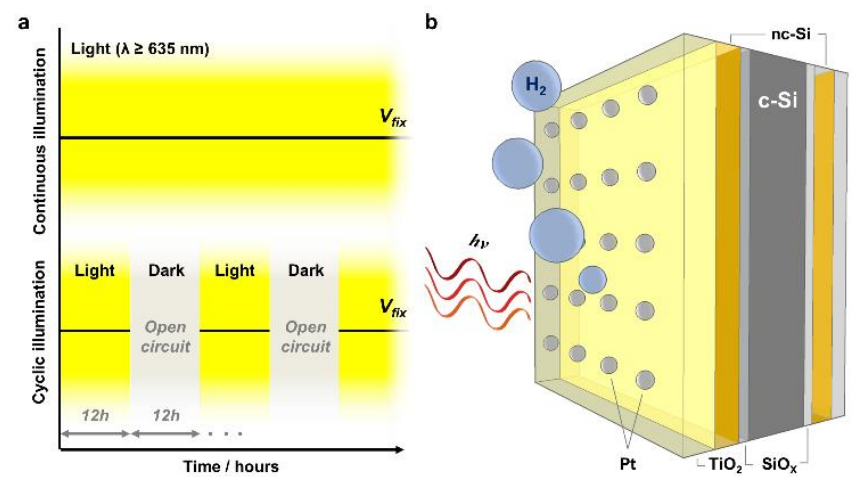

Figure 1. Light illumination conditions (a) and schematic (b) of the $\mathrm{TiO}_{2}$ protected MOS-based c-Si photocathode $\left(\mathrm{p}^{+} \mathrm{nc}-\mathrm{Si} / \mathrm{SiO} \times \mathrm{p}-\mathrm{Si} / \mathrm{SiO} \times \mathrm{n}^{+} \mathrm{nc}-\mathrm{Si}\right)$ with $\mathrm{Pt}$ nanoparticles used for the stability experiments. 

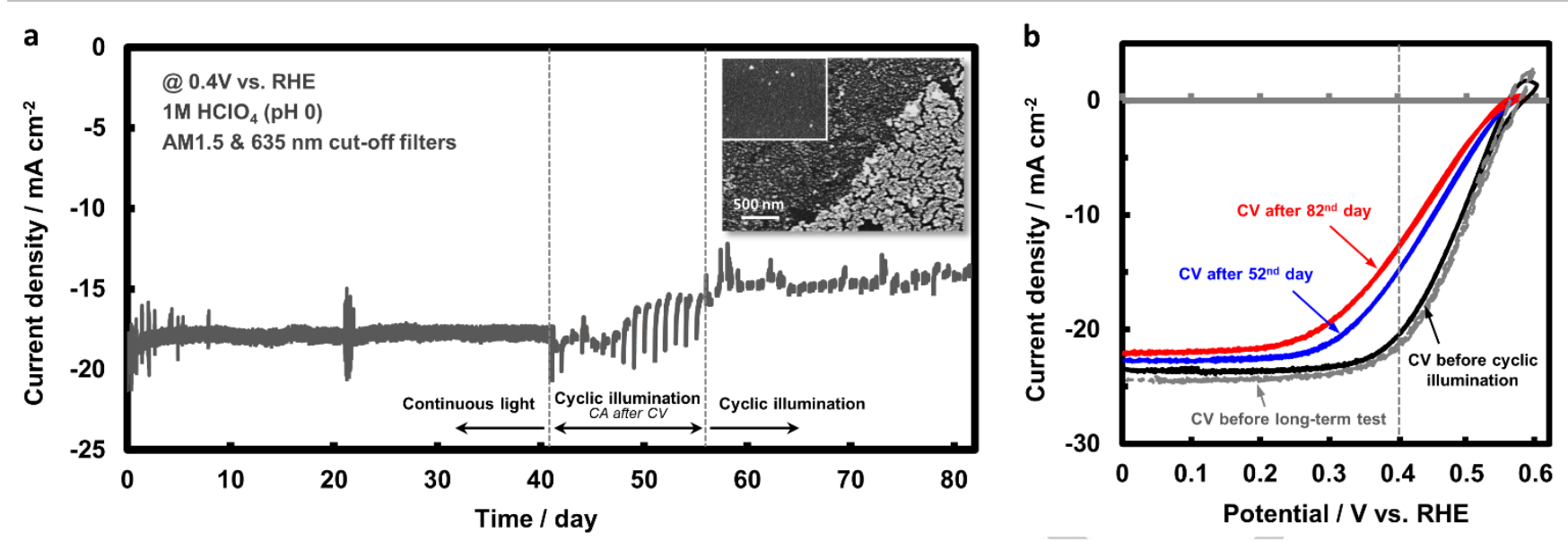

Figure 2. Chronoamperometry $(\mathrm{CA})$ of the sample measured at $0.4 \mathrm{~V}_{\mathrm{RHE}}$ (voltage vs. reversible hydrogen electrode) in $1 \mathrm{M} \mathrm{HClO} \overline{\mathrm{O}}_{4}(\mathrm{a})$ and cyclic voltammogram (CV) curves (b) taken prior to the CA measurement under continuous light (dashed grey) and cyclic illumination (black), after the $52^{\text {nd }}$ day (blue), and after the $82^{\text {nd }}$ day (red). SEM image of the sample surface after the long-term experiment also can be found in inset. Zoomed-in image is the surface after DI water rinsing. Note that CA and CV data obtained under the continuous light were reproduced with permission from ref. [16]. Copyright 2017 by Elsevier.

fixed potential of $0.4 \mathrm{~V}$ vs. RHE with both the continuous irradiation and the cycled irradiation. The $635 \mathrm{~nm}$ cut-off filter was used to simulate the red part of the solar spectrum under the assumption that the $\mathrm{Si}$ is used as a bottom cell in a tandem water splitting device. Figure 2 a shows an initial degradation during the first day, which is likely due to adsorption of impurities, ${ }^{[14,17]}$ and then no noticeable signs of further degradation in photocurrent $\left(J_{p h}\right)$ for the following 40 days. However, once the electrode was subjected to cycling in a 12 hour on/12 hour off manner, a significant instability in the photocurrent emerges. From day 41 to day 56 cyclic voltammograms (CV; -0.02 $0.58 \mathrm{~V}$ vs. RHE) were recorded in between the on-off cycles. A close look (Fig. S2) at each cycle reveals that the sample partially regains the activity and then the $J_{p h}$ degrades quickly.

From day 57 to day 82 the on/off cycling continued, however, cyclic voltammograms were not done in between cycles (except for a final CV at the end of day 82). Actually, the intermediate CV scans during the previous period (from day 41 to day 56) led to an increased degradation rate while some of the activity was regained immediately following the $\mathrm{CV}$. The reason why the cyclic voltammograms could have an impact on the stability can be rationalized by considering the electrode/electrolyte surface potential in both cases. During illumination the device operates at $0.4 \mathrm{~V}$ vs. RHE. However, it is important to note that this is the applied potentiostatic potential, and not the actual potential at the semiconductor/catalyst interface, due to the photovoltage developed by the photoelectrode. The actual surface potential should be whatever potential the catalyst needs to evolve $\mathrm{H}_{2}$ at the relevant current density. Since Pt was used as a catalyst, this should be very close to $0 \mathrm{~V}$ vs. RHE. Thus during irradiation the surface was slightly cathodic of $0 \mathrm{~V}$ vs. RHE, whereas when the cell was in the dark it was at a potential anodic of $0 \mathrm{~V}$ vs. RHE (since it was not producing $\mathrm{H}_{2}$ in the dark). Thus, the applied potential differs from the surface potential by the photovoltage. As the potentiostat does a cyclic voltammogram, it can force the surface potential to be slightly more cathodic than $0 \mathrm{~V}$ vs. RHE.

The cyclic voltammograms in Figure $2 \mathrm{~b}$ provide further clues to the degradation method. The CV after 41 days is very similar to the initial CV indicating that our electrode is stable under steady state conditions. However, the CVs performed after the $52^{\text {nd }}$ and the $82^{\text {nd }}$ day exhibit a markedly worse performance in the Tafel regime ( 0.4 to $0.5 \mathrm{~V}$ vs. RHE) as well as a slight decrease in saturation current. The CV's demonstrate that the loss in performance in Fig. $2 \mathrm{a}$ is primarily a catalysis issue rather than a light absorption issue. Previous works have shown that a poor fillfactor is indicative of a low amount of active Pt sites. ${ }^{[18]}$ Since this cell initially had a good fill-factor, this loss could be due to the physical loss of $\mathrm{Pt}$ co-catalyst or to deactivation by poisoning or contamination of the Pt surface.

The scanning electron microscopy (SEM) image (inset in Fig. 2a) revealed that the surface of the photocathode is partly covered with a thick bright layer, while the $\mathrm{TiO}_{2}$ in other areas is well preserved. The XPS spectra from the sample right after the Pt photodeposition (via reduction of the Pt-dihydrogen dinitrosulphatoplatinum(II) salt (Pt-DNS, Johnson Matthey) as described in elsewhere $)^{[14,16,19]}$ and the XPS after the long-term experiment (Fig. 3a) shows no obvious peak from the elemental
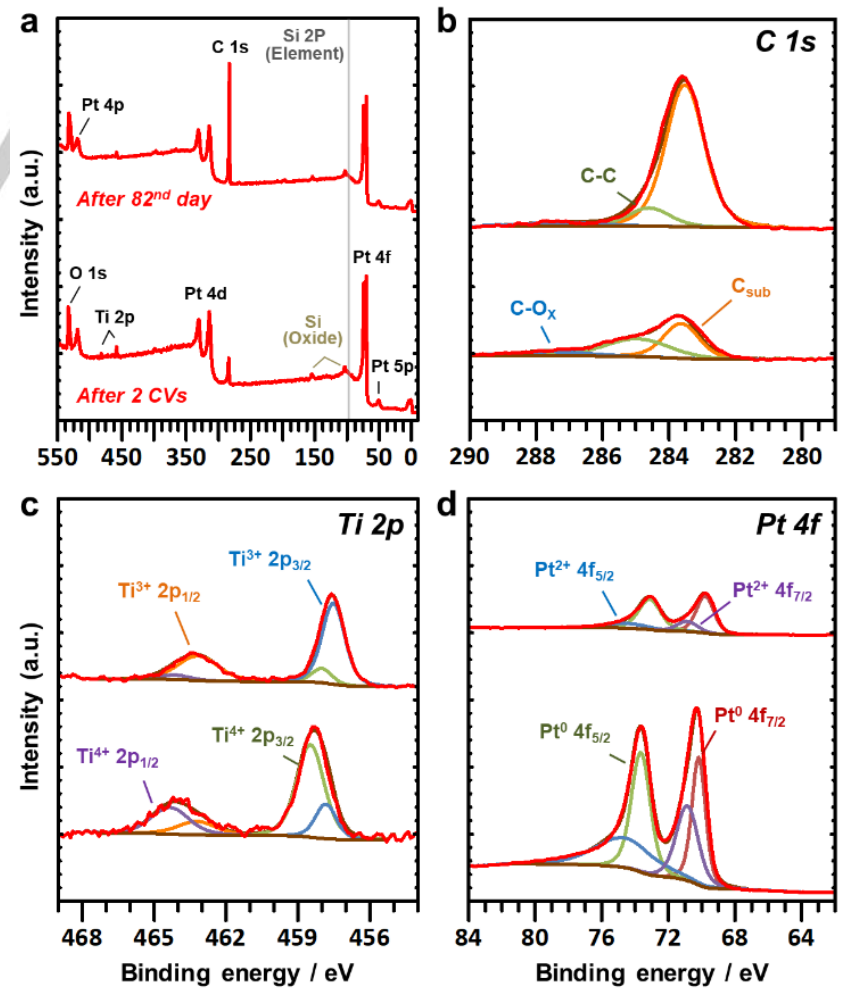

Figure 3. Survey scan of XPS data of the sample before and after the stability experiment (a). Magnified view of the XPS spectra of the C 1s (b), Ti $2 p(c)$, and $\mathrm{Pt} 4 \mathrm{f}(\mathrm{d})$ are shown with the deconvoluted peak assignments. 
Si $(99.4 \pm 0.3 \mathrm{eV})$ which corroborates the previous contention that $\mathrm{Si}$ is well protected by the $\mathrm{TiO}_{2}$. An interesting feature is that the carbon peak showed a drastic change after the long-term experiment. In particular, the $\mathrm{C}_{\text {Sub }}(\mathrm{C}$ bonded to the substrate, i.e. $\mathrm{C}-\mathrm{Ti})^{[20]}$ was significantly increased is carbon bonded to the substrate (Fig. 3b), while other peaks (Fig. 3c and d) especially Pt reduced significantly. The XPS survey (Fig. 3a) and EDX analysis (Fig. S3) of these areas did not show any additional foreign species, but taken together with the increased carbon signal we tentatively assign the bright layer on top of the $\mathrm{TiO}_{2}$ in the SEM to be carbonaceous material. It is plausible that the decomposition of the epoxy sealant (probably forming vinyl radicals) ${ }^{[21]}$ in harsh acidic condition and led to the carbon contamination. The negative shift of the $\mathrm{Ti} 2 \mathrm{p}$ due to relative increase of $\mathrm{Ti}^{3+}$ peaks in the sample after the long-term experiment is likely attributed to the hydroxide formation by the presence of $\mathrm{H}_{2} \mathrm{O}$ as described elsewhere. ${ }^{[22,23]}$ In the case of $\mathrm{Pt} 4 \mathrm{f}$, decrease of the $\mathrm{Pt}^{2+}$ peak led to the slight negative shift and this might be due to reduction of the Pt-DNS salt during a continuous reduction process (i.e., $\mathrm{Pt}$ metal formation).

In order to investigate the effect of UV light exposure, cells were first contaminated with adventitious carbon. This was done by taking a fresh photoelectrode and then doing 12 hours on/off cycling on it for 12 days using only red light $(\lambda>635 \mathrm{~nm})$. The electrodes were then illuminated with white light (AM1.5) for 12 hours, and a CV following this test showed the contamination still remained. Following this test, the photoelectrodes were illuminated with just UV light $\left(2 \mathrm{~mW} \mathrm{~cm}^{-2}\right.$, the spectrum shown in Fig. S4) for 12 hours at $0 V_{\text {RHE, }}$ which produced a current of $\approx 0.2$ $\mathrm{mA} \mathrm{cm}{ }^{-2}$.
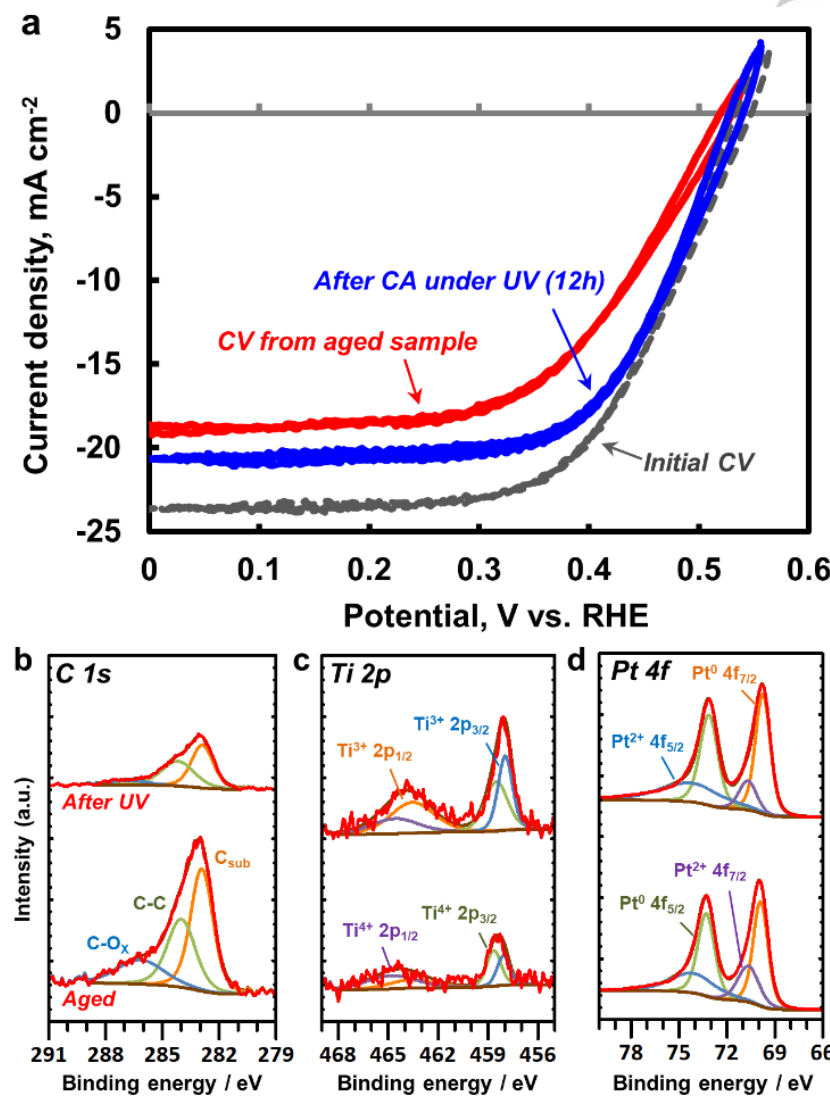

Binding energy $/ \mathrm{eV}$ Binding energy / eV Binding energy / ev

Figure 4. CV characterization (a) of the photocathode before $(0 \mathrm{~h}$, grey dots), after 12 days aging (red), and after the UV treatment for 12h. XPS spectra of the $\mathrm{C} 1 \mathrm{~s}(\mathrm{~b}), \mathrm{Ti} 2 \mathrm{p}(\mathrm{c})$, and $\mathrm{Pt} 4 \mathrm{f}(\mathrm{d})$ are also shown with the deconvoluted peak assignments.
The CV curve after the UV light exposure (Fig. 4a) shows a remarkable recovery of the slope almost to that of the initial $\mathrm{CV}$ curve suggesting that the degradation in photocurrent during the CA measurement was not a result of damage to the photoelectrode. However, there is a disparity in saturation photocurrent $\left(\sim 3 \mathrm{~mA} \mathrm{~cm}^{-2}\right.$ at $\left.0 \mathrm{~V}\right)$ between the initial CV curve and the one after the UV treatment. This might be due to unremoved carbonaceous contaminants which can lead to parasitic absorption loss. XPS data in Fig. $4 \mathrm{~b}$ confirms that carbon peaks were significantly reduced after the UV treatment, while the other peaks ( $\mathrm{Ti} 2 \mathrm{p}$ and $\mathrm{Pt} 4 \mathrm{f}$ in Figs. $4 \mathrm{c}$ and $\mathrm{d}$ ) increased drastically, showing an opposite trend to that of measured after the 82-days test as shown in Figs. 3b-d. Formation of oxidative oxygen or hydroxide radicals by the activated $\mathrm{TiO}_{2}$ under the UV light might decompose the organic contamination, such as carbon, as suggested by Hoffmann et al. ${ }^{[24]}$

Taken together, these observations indicate that both the Pt cocatalyst and the photocathode itself remains well preserved without irreparable damage. The UV-induced performance recovery likely results from the photocatalytic cleaning effect of the $\mathrm{TiO}_{2}$ layer as demonstrated elsewhere. ${ }^{[25-27]}$ It is worth mentioning that the $\mathrm{CV}$ after the white light (full spectrum) exposure on the aged sample showed no obvious change in the curve slope or the saturation photocurrent level (Fig. S5).

In conclusion, we have shown the feasibility of a highly stable HER both under the continuous and cyclic light conditions for 82 days with a $\mathrm{TiO}_{2}$ protected MOS-Si photocathode. To the best of our knowledge, this is the longest reported stability for the PEC photocathode system, although it should be stressed that this addresses only 'half of the water-splitting problem. We also concluded that the photocurrent loss during the long-term stability test is mainly due to carbon contamination. In addition, we observe promising evidence that contamination can be simply removed under UV light which is likely to be caused by the photocatalytic action of the $\mathrm{TiO}_{2}$.

\section{Acknowledgements}

The authors acknowledge the support from the VILLUM Center for Science of Sustainable Fuels and Chemicals which is funded by the VILLUM Fonden research grant (9455).

Keywords: PEC • water splitting reaction $\cdot$ hydrogen evolution reaction $\cdot$ photocathode $\cdot$ titanium oxide

B. D. James, G. N. Baum, J. Perez, K. N. Baum, Technoeconomic Analysis of Photoelectrochemical (PEC) Hydrogen Production, Arlington, VA, 2009.

M. M. May, H.-J. Lewerenz, D. Lackner, F. Dimroth, T. Hannappel, Nat. Commun. 2015, 6, 8286.

J. W. Ager, M. R. Shaner, K. A. Walczak, I. D. Sharp, S. Ardo, Energy Environ. Sci. 2015, 8, 2811-2824.

F. Urbain, V. Smirnov, J.-P. Becker, A. Lambertz, F. Yang, J. Ziegler, B. Kaiser, W. Jaegermann, U. Rau, F. Finger, Energy Environ. Sci. 2016, 9, 145-154.

W.-H. Cheng, M. H. Richter, M. M. May, J. Ohlmann, D. Lackner, F. Dimroth, T. Hannappel, H. A. Atwater, H.-J. Lewerenz, ACS Energy Lett. 2018, DOI 10.1021/acsenergylett.8b00920.

D. Bae, B. Seger, P. C. K. Vesborg, O. Hansen, I. Chorkendorff,

Chem. Soc. Rev. 2017, 46, 1933-1954.

[7] A. Azarpira, M. Lublow, A. Steigert, P. Bogdanoff, D. Greiner, C. A. Kaufmann, M. Krüger, U. Gernert, R. Van De Krol, A. Fischer, et al., 
Adv. Energy Mater. 2015, 5, 1402148.

[8]

C. U. Maier, M. Specht, G. Bilger, Int. J. Hydrogen Energy 1996, 21, 859-864.

[9] L. A. King, T. R. Hellstern, J. Park, R. Sinclair, T. F. Jaramillo, ACS Appl. Mater. Interfaces 2017, 9, 36792-36798.

[10] L. Liu, H. Hou, L. Wang, R. Xu, Y. Lei, S. Shen, D. Yang, W. Yang, Nanoscale 2017, 9, 15650-15657.

[11] M. Pourbaix, Atlas of Electrochemical Equilibria in Aqueous Solutions, National Association Of Corrosion Engineers, Houston, TX, 1974.

[12] J. L. Young, K. X. Steirer, M. J. Dzara, J. A. Turner, T. G. Deutsch, J. Mater. Chem. A 2016, 4, 2831-2836.

[13] W. A. Smith, I. D. Sharp, N. C. Strandwitz, J. Bisquert, Energy Environ. Sci. 2015, 8, 2851-2862.

[14] D. Bae, S. Shayestehaminzadeh, E. B. Thorsteinsson, T. Pedersen, O. Hansen, B. Seger, P. C. K. Vesborg, S. Ólafsson, I. Chorkendorff, Sol. Energy Mater. Sol. Cells 2016, 144, 758-765.

[15] N. Macauley, D. D. Papadias, J. Fairweather, D. Spernjak, D. Langlois, R. Ahluwalia, K. L. More, R. Mukundan, R. L. Borup, J. Electrochem. Soc. 2018, 165, F3148-F3160.

[16] D. Bae, T. Pedersen, B. Seger, B. landolo, O. Hansen, P. C. K. Vesborg, I. Chorkendorff, Catal. Today 2017, 290, 59-64.
E. Kemppainen, A. Bodin, B. Sebok, T. Pedersen, B. Seger, B. Mei, D. Bae, P. C. K. Vesborg, J. Halme, O. Hansen, et al., Energy Environ. Sci. 2015, 8, 2991-2999.

[19] D. Bae, T. Pedersen, B. Seger, M. Malizia, A. Kuznetsov, O. Hansen, I. Chorkendorff, P. C. K. Vesborg, Energy Environ. Sci. 2015, 8, 650-660.

[20] A. Z. Abidin, R. Kozera, M. Höhn, I. Endler, M. Knaut, A. Boczkowska, A. Czulak, P. Malczyk, N. Sobczak, A. Michaelis, Thin Solid Films 2015, 589, 479-486.

[21] X. Zhang, Y. Wu, X. Chen, H. Wen, S. Xiao, Polymers (Basel). 2017, 9, 1-9.

[22] X. Wang, Y. Li, H. Song, Y. Huang, R. Su, F. Besenbacher, RSC Adv. 2016, 6, 18333-18339.

[23] M. Zhu, R. Wang, C. Chen, H. Zhang, G. Zhang, RSC Adv. 2017, 7, 12534-12540.

[24] M. R. Hoffmann, S. T. Martin, W. Choi, D. W. Bahnemann, Chem. Rev. 1995, 95, 69-96.

[25] S. Banerjee, D. D. Dionysiou, S. C. Pillai, Appl. Catal. B Environ. 2015, 176-177, 396-428.

[26] U. Diebold, Surf. Sci. Rep. 2003, 48, 53-229.

[27] S. II In, P. C. K. Vesborg, B. L. Abrams, Y. Hou, I. Chorkendorff, J. Photochem. Photobiol. A Chem. 2011, 222, 258-262. 
Entry for the Table of Contents (Please choose one layout)

Layout 1:

\section{COMMUNICATION}

Text for Table of Contents

Layout 2:

\section{COMMUNICATION}

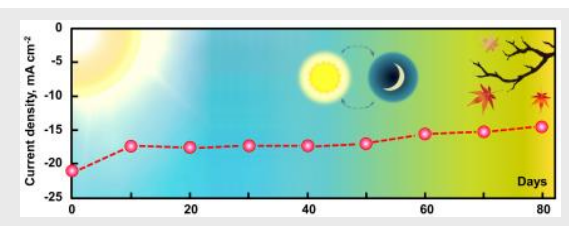

Extremely reliable $\mathrm{PEC} \mathrm{H}_{2}$ production: $\mathrm{A} \mathrm{TiO}_{2}: \mathrm{H}$ protected c-Si photocathode with metal-oxide-semiconductor junctions exhibits long-term hydrogen evolution performance (82 days) in $1 \mathrm{M} \mathrm{HClO}$ under continuous and day/night cyclic illumination condition. Characterization of the sample reveals a carbon contaminant leading to activity loss which is easily removed by UV light exposure.
Author(s), Corresponding Author(s)*

Page No. - Page No.

Title

Dowon Bae, Brian Seger, Ole Hansen, Peter C.K. Vesborg, and Ib Chorkendorff*

Page No. - Page No.

Durability testing of photoelectrochemical hydrogen production under day/night light cycled conditions 